\title{
Induction of testis-ova in nile tilapia (Oreochromis niloticus) exposed to $17 \beta$-estradiol
}

\author{
Piya Kosai ${ }^{1}$, Wannee Jiraungkoorskul ${ }^{1 *}$, Chaivira Sachamahithinant ${ }^{2}$, \\ Kanitta Jiraungkoorskul ${ }^{3}$ \\ ${ }^{1}$ Department of Pathobiology, Faculty of Science, Mahidol University, Bangkok, Thailand; \\ *Corresponding Author: tewjr@mahidol.ac.th \\ ${ }^{2}$ Mahidol University International College, Mahidol University, Salaya Campus, Nakhonpathom, Thailand \\ ${ }^{3}$ Department of Occupational Health and Safety, Faculty of Public Health, Mahidol University, Bangkok, Thailand
}

Received 12 November 2010; revised 27 December 2010; accepted 28 December 2010.

\begin{abstract}
The efficacy of Endocrine Disrupting Compounds (EDCs), 17 $\beta$-estradiol was tested on the fish Oreochromis niloticus in order to understand the intersex relationship of fish, in which sequential hermaphrodism can consist of a male changing into a female (protandry) or a female changing into a male (protogyny). The fish were equally divided into 3 groups. The first group was the control group; the second and third groups were treated with 10 and $100 \mu \mathrm{g} \mathrm{L}^{-1}$ of $17 \beta$-estradiol, respectively, for 30 days. The overall result in this experiment had no significant effect on the growth parameters. Among the two treated groups, the low concentration group shows results similar to those of the control groups. The high concentration group shows changes to the male reproductive system with the appearance of the testis-ova present resulting in an intersex condition of the male gonads. With this experiment, it can be concluded that $17 \beta$-estradiol at high concentration reveals positive changes towards the male reproductive system of the fish, Oreochromis niloticus.
\end{abstract}

Keywords: Oreochromis niloticus; Nile Tilapia; Endocrine Disruption; Xenoestrogens; Testis-Ova; $17 \beta$-Estradiol

\section{INTRODUCTION}

"Endocrine Disruption" has been defined as exogenous chemicals that alter the functions of the endocrine system and consequently cause adverse health effects in the intact organisms [1]. Endocrine Disruptor Screening and Testing Advisory Committee were assigned the task of making recommendations for the development of testing and screening programs for endocrine disrupters [2]. Likewise, the Organization for Economic Co-operation and Development also established a special activity for endocrine disrupter testing and assessment [3]. Subsequently, the World Health Organization tasked the international program on chemical safety with preparing a report describing the global assessment of the scientific literature on endocrine disrupting chemicals [4].

There is increasing concern about male reproductive disorders in humans, and widespread sexual disruption among wildlife. Numerous studies have documented generation rises in testicular cancer, declines in sperm quality and increases in infertility [5]; increases in rates of male infants born with incompletely-formed penises and undescended testicles [6,7]. The ratio of baby boys to baby girls is declining in the U.S. and other industrialized countries [8]. The causes of these worrying trends are largely unknown, but one possibility is that they might be linked to endocrine disrupting chemicals (EDCs).

Among EDCs found in the aquatic environment are the steroid estrogens such as $17 \beta$-estradiol, estrone and estriol [9]. In oviparous fish species, the production of vitellogenin, an egg yolk protein precursor, is a critical step for successful reproduction in females. Normally, only mature females produce enough endogenous estrogen to induce vitellogenesis in fish, but exposure to estrogenic chemicals in the external environment can trigger this response in male and juvenile fish as well. Many wildlife species, especially fish, show signs of feminisation, with male fish producing large quantities of vitellogenin and developing sexual organs that are intermediate between male and female features, resulting in so-called intersex fish [10]. In the aquatic environment, EDCs are easily bioavailability to fish through a variety 
of routes, including aquatic respiration, osmoregulation and maternal transfer of contaminants in lipid reserves of eggs [11]. Dermal contacts with contaminated sediments or ingestion of contaminated food are additional exposure routes. EDCs that are apt to cause endocrine modulation in vivo have one of three characteristics: they are present in the environment at high concentrations, they are persistent and bioaccumulative, or they are constantly entering the environment [12]. EDCs that are resistant to biodegradation and are lipophilic may bioaccumulation in exposed organisms. Such EDCs include organochlorine pesticides, polychlorinated biphenyls and alkylphenols, all of which are found in aquatic environments. Other EDCs i.e., bisphenol A and 17 $\beta$-estradiol, do not bioaccumulation to any extent but are constantly entering the aquatic environment through operations such as effluent from sewage treatment works and run-off from concentrated animal feeding operations [13].

In the present study, we describe the normal histology of Nile tilapia (Oreochromis niloticus) reproductive organ, and illustrate histopathological alterations in this organ associated with endocrine disrupting chemicals in the laboratory studies.

\section{MATERIAL AND METHODS}

\subsection{Experimental Fish}

This study was performed at the Department of Pathobiology, Faculty of Science, Mahidol University, Bangkok, Thailand. Nile tilapia, O. niloticus, was juvenile and young adults with $1.22 \pm 0.45 \mathrm{~g}$, and $4.25 \pm$ $0.58 \mathrm{~g}$ body weight, respectively. Tap water was filtered to eliminate chemical contamination. The physicochemical characteristics of water were measured daily, according to the experimental procedures described in Standard Methods for the Examination of Water and Wastewater [14]. Under laboratory condition, fish were acclimated for 30 days at $29.0 \pm 1.0^{\circ} \mathrm{C}, \mathrm{pH}=6.6-7.0$, total hardness $=68-80 \mathrm{mg} \mathrm{L}^{-1}\left(\right.$ as $\left.\mathrm{CaCO}_{3}\right)$, alkalinity $=$ $75-80 \mathrm{mg} \mathrm{L}^{-1}$ and conductivity $=190-220 \mu \mathrm{mhos} \mathrm{cm}^{-1}$. A 16:8 hour light-dark cycle was maintained throughout. Chlorine residual and ammonia were below detection limits. Fish were fed twice a day with 37\%-protein commercial fish food (Charoen Pokphand Group, Bangkok, Thailand). The quantity of food was $2 \%$ of the initial body weight per day. The animal care and handling in this research was performed following the instruction of the Mahidol University-Institutional Animal Care and Use Committee (MU-IACUC). Therefore, this research was followed the mammal animal care and use i.e., 1) Use, care and transportation of fish for toxicopathological testing was complied with all applicable animal welfare laws. 2) Number of fish was kept to the minimum requirement for achieve scientifically valid results. 3) All protocols were taken to avoid the discomfort, distress or pain in the fish. 4) The appropriate dosage of the anesthesia was $200 \mathrm{mg} \mathrm{L}^{-1}$ ethyl-3-aminobenzoate methanesulfonate salt (MS222, Sigma) and the euthanasia was overdose of this chemical.

\subsection{Experimental Design}

The experiments were carried out in three glass aquaria containing of the same physicochemical characteristics of water, with continuous aeration. Fish $(n=30)$ were randomly assigned to the three groups: Group 1 was the control group; Group 2 and 3 were the treated groups with 10 and $100 \mu \mathrm{g} \mathrm{L}^{-1}$ of $17 \beta$-estradiol, respectively. After 30 days exposure, fish from each aquarium were anesthetized. Dissection of fish was performed after completing the external examination. The reproductive organ was removed and prepared for histopathological studies.

\subsection{Specimen Preparation for Light Microscopic Studies}

The procedures for light microscopy were modified Humason's method [15]. Briefly, small pieces of tissues were fixed in the $10 \%$ buffered formaldehyde for $24 \mathrm{~h}$, dehydrate through a graded series of ethanol and clear with xylene solutions. They were embedded in a block using melted paraffin at the embedding station. The paraffin blocks were sectioned at $4 \mu \mathrm{m}$ thickness using a rotary microtome, and stained with hematoxylin and eosin. The tissue glass slides were examined for abnormalities by a Nikon E600 light microscope and photographed by a Nikon DXM 1200 digital camera (Tokyo, Japan).

\section{RESULTS}

Female gonads were classified of being in one of six maturation stages according to a classification scale proposed by Gupta [16]. Stage I corresponded to immature ovaries, with youngest oocytes diameter $0.05-0.15$ $\mathrm{mm}$. Stage II showed maturing oocytes, characteristically containing small vacuoles in the cytoplasm diameter $0.15-0.3 \mathrm{~mm}$. Stage III was characterized by advanced maturing oocytes diameter $0.3-0.7 \mathrm{~mm}$. Then, as the ovaries mature, from Stage III onward a number of ova undergo a process of resorption. At this stage the whole follicle loosed its shape and was described as an atretic follicle. Stage IV represented mature oocytes diameter $0.7-0.8 \mathrm{~mm}$, filled with chromophilic yolk. At Stage $\mathrm{V}$, the mature ova increased in size with yolk accumulation, and at this stage they were ripe. At Stage VI, the ovary did not differ greatly from the previous stage, 
with the remaining ova not as closely packed together since some had been extruded.

No recognizable changes were observed in the female reproductive system of the control (Figures 1-2) and low (Figure 3) exposure groups throughout this experiment. The majority of females were classified as being at Stage I, characteristically showing immature ovaries, with the presence of young oocytes at different stages of development. Female exposed to high $17 \beta$-estradiol (Figure 4) was classified as being at Stage II with maturing oocytes, characteristically containing small vacuoles in the cytoplasm.

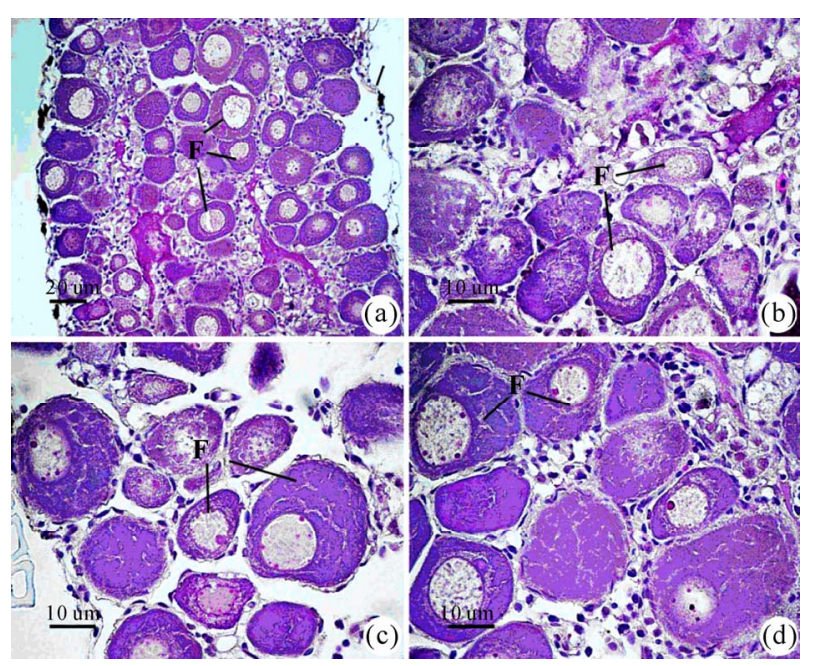

Figure 1. Low and high magnification light micrographs of ovary in the control group of juvenile $O$. niloticus. The ovary was filled with primary follicles $(\mathrm{F})$ containing oocytes which had a large, light staining nucleus and strongly basophilic cytoplasm. Note tubnica albuginea (T) surrounding the ovary was very thin.

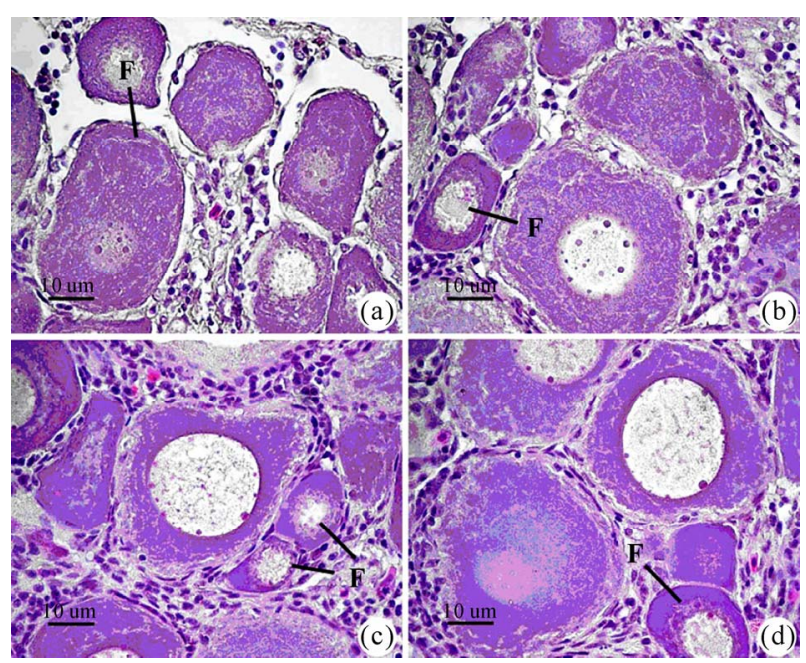

Figure 2. Low and high magnification light micrographs of ovary in the control group of young adult $O$. niloticus, similarly with the juvenile ovary.

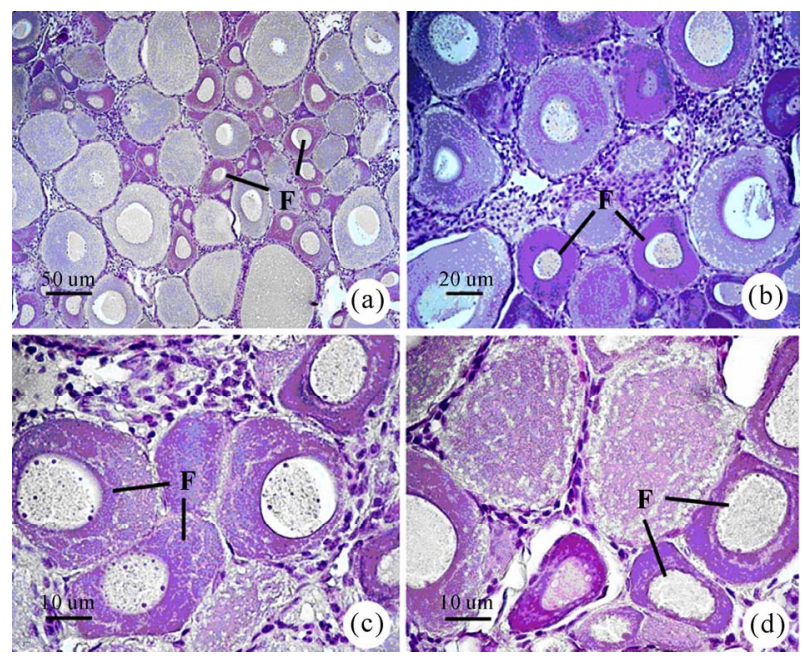

Figure 3. Low and high magnification light micrographs of ovary in the low concentration $17 \beta$-estradiol group of $O$. niloticus showing the internal structure similarly with those of control group.
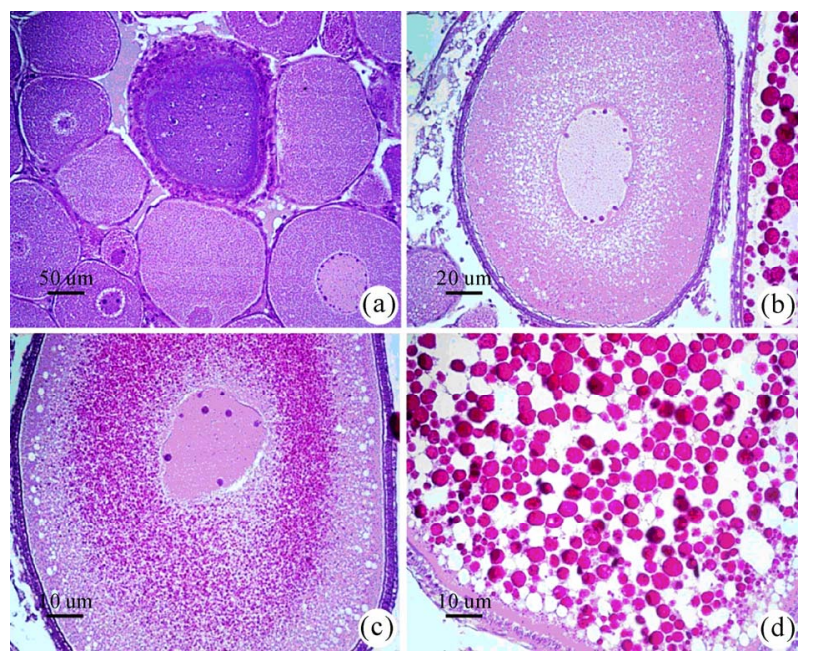

Figure 4. Low and high magnification light micrographs of ovary in the high concentration $17 \beta$-estradiol group of $O$. niloticus were classified as being at Stage II with maturing oocytes, characteristically containing small vacuoles in the cytoplasm.

Light microscopic studied of the longitudinal sections showed that the control testes of $O$. niloticus consist of lobules separated from each other by interstitial tissue. The interstitial tissue became very thin and compressed in the maturing testis. The testes consisted of lobules with cysts in different stages of development. Spermatozoa could be observed in the lumen of the lobule. The lobules were lined in the inside by Sertoli cells, which were important for the support and nutrition of developing spermatozoa. In order to describe the testicular development, and to use the testis as a reproductive biomarker, it was necessary to determine the repro- 
ductive maturity of each fish testis that was examined. This was done by using the classification system that recognized four developmental gonad stages (stages I-IV) for males.

The histological characteristic of the gonad stages that were used during this investigation were adapted from Gupta [16], Nagahama [17], and Goodbred et al. [18]. The stages were based on the maturity of the predominant stage of spermatogenesis. Stage I: Immature testes were recognized by the absence of spermatogenic activity in the interstitial tissue and the presence of primarily spermatocytes. No spermatozoa are present in the lobules. Stage II: Early spermatogenesis was characterized by mostly thin interstitial tissue and the presence of primarily immature cells (spermatocytes to spermatids); however, some spermatozoa were also present. Stage III: Mid-spermatogenesis, the interstitial tissue was moderately thick and some proliferation and maturation of the sperm could be observed; spermatocytes, spermatids and spermatozoa were present in roughly equal proportion. Stage IV: Late spermatogenesis, the interstitial tissue was thick. Although all cell types were represented, spermatozoa predominate in this stage. Stages II through IV were characteristic of sexually mature fish, with the least activity occurring in off-season (stage II) and the most activity taking place immediately prior to and during the spawning season (stage IV).

No recognizable changes were observed in the male reproductive system of the control (Figure 5) and low (Figure 6) exposure groups throughout this experiment. The testes had normal appearance; containing cells at all spermatogenic stages, and was classified as maturing testes (Stage II). Histological the testis of the fish consisted of lobules of various shapes, which were connected with each other by thin connective tissues. The interstitial cells were observed in between the testis lobules.

During the spermatogenic process, the sperm mother cell in the germinal epithelium multiplied and produced the primary and secondary spermatocytes, spermatids, and sperms. The lumina were filled with spermatozoa and the lobules contained numerous spermatogenic cysts. The histological alteration of the testes of high (Figures 7-8) exposure groups showed normal appearance of the testis lobules, however, there were found testis-ova in some areas.

\section{DISCUSSION}

Several endocrine disrupting chemicals including xenoestrogens or estrogenic chemicals released into the aquatic environment have the potential to disrupt the endocrine systems, especially of fish and subsequently cause adverse effects on the sexual development and reproduction [13].
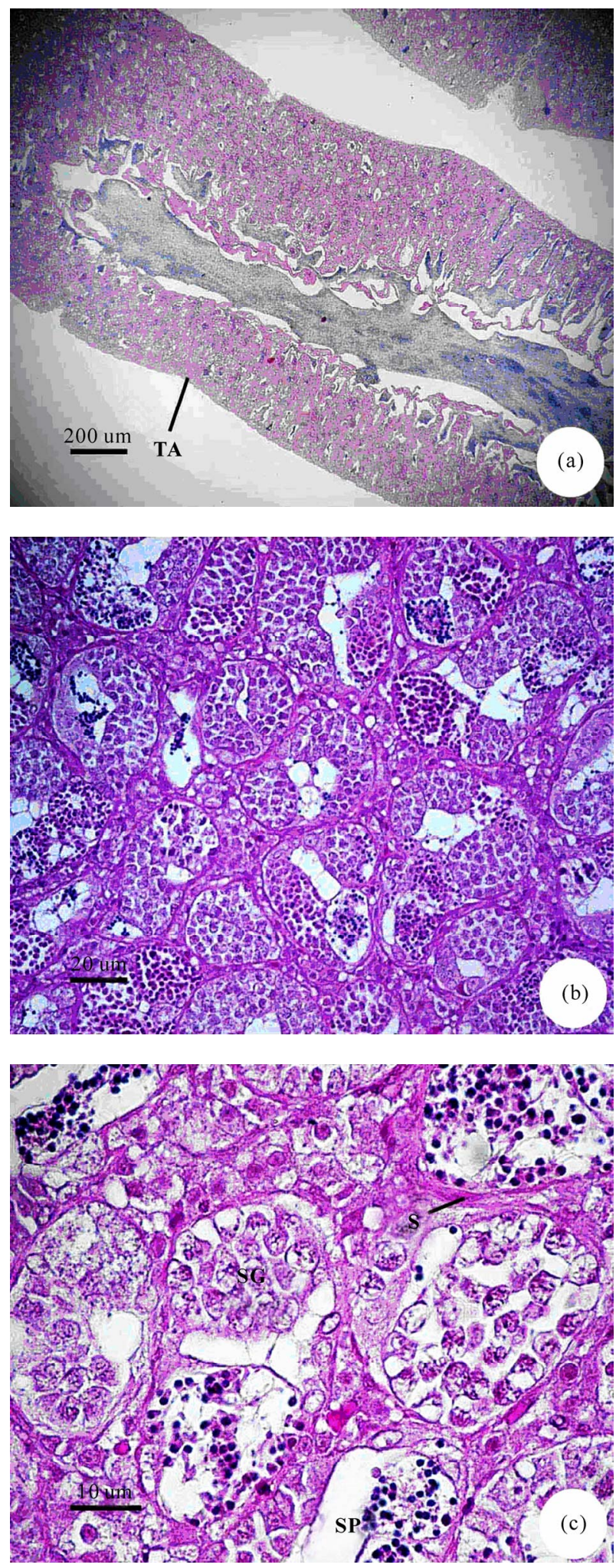

Figure 5. Low and high magnification light micrographs of testis in the control group of $O$. niloticus showing the externally testis is covered by the tunica albuginea (TA). Note the position of the Sertoli cell (S), which lines the lobule; $\mathrm{SG}=$ spermatogonia; $\mathrm{SP}=$ spermatozoa. 

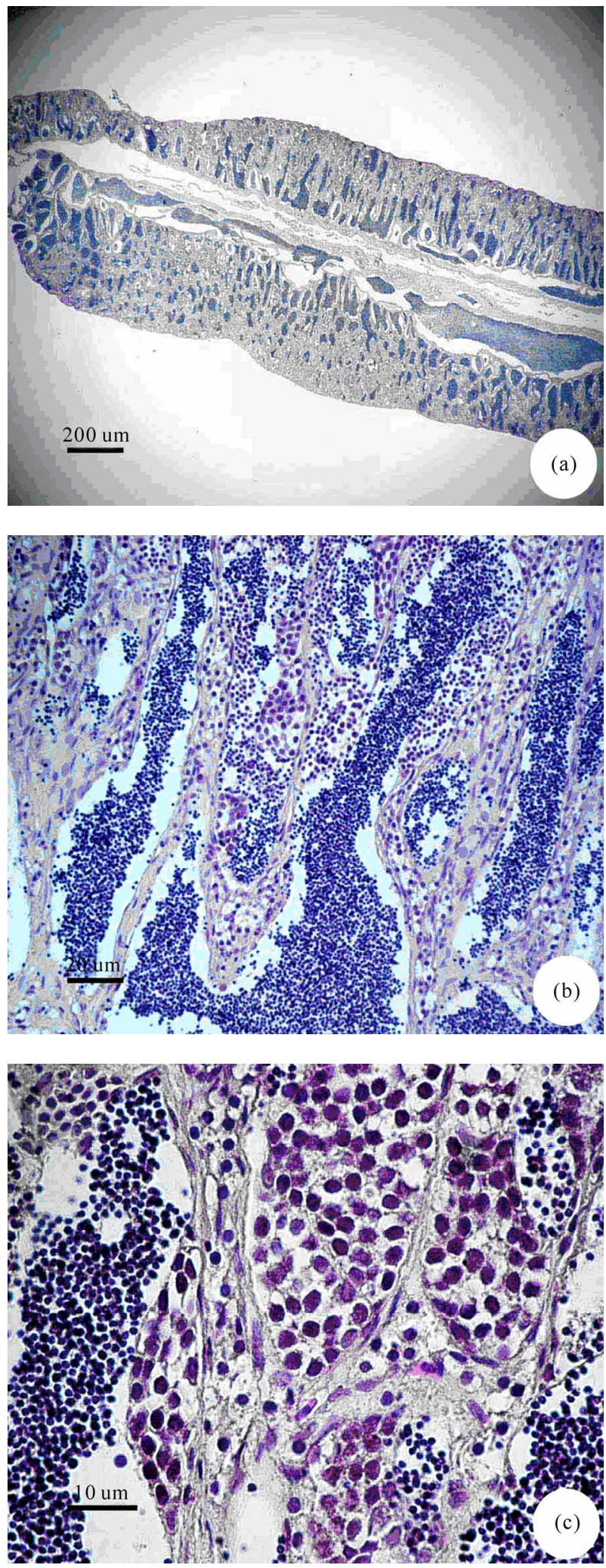

Figure 6. Low and high magnification light micrographs of testis in the low concentration 17 $\beta$-estradiol group of $O$. niloticus showing the internal structure similarly with those of control group.
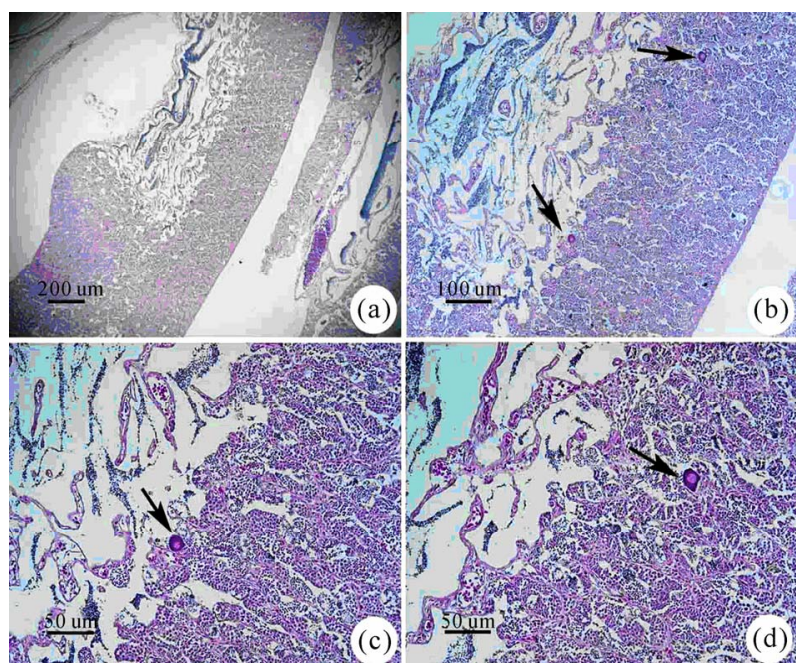

Figure 7. Low and high magnification light micrographs of testis in the high concentration group of $O$. niloticus. Note arrows $=$ testis-ova.

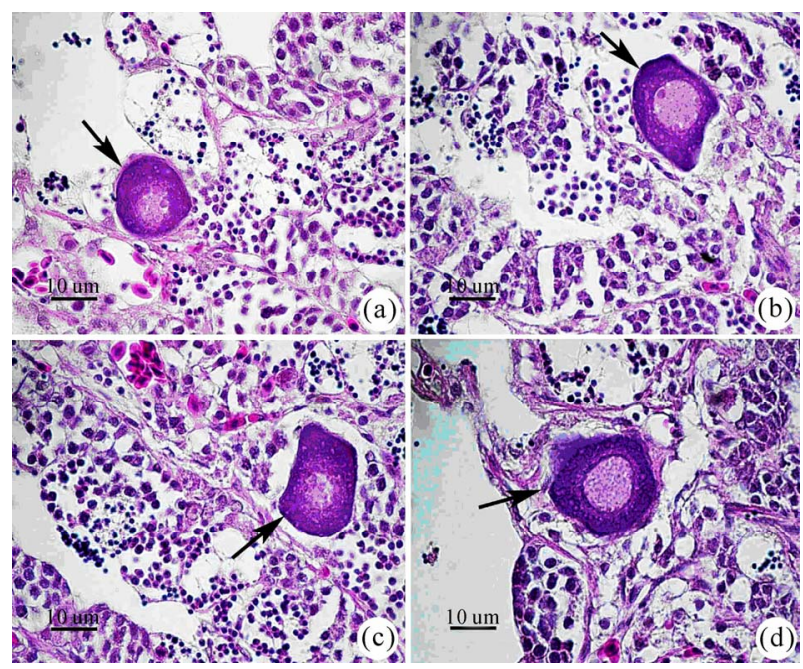

Figure 8. Light micrographs of testis in the high concentration group of $O$. niloticus. Note arrows = testis-ova.

Xenoestrogens can interfere with natural estrogens by binding to the physiological estrogen receptor and thus mimicking or degradation natural estrogen [19]. The consequences of exposure to xenoestrogens may be reproductive disorders such as reduced fertility, reduced hatchability, reduced viability of off-spring, impaired hormone activity, structural abnormalities of the reproductive tract, and altered adult sexual behavior [20-22].

Studies regarding 17 $\beta$-estradiol effects on fish have been focused on endocrine aspects, mainly reproduction. It is known that it may alter gonadosomatic index in males, reduce egg production in females, induce vitellogenesis in males and juveniles as well as decrease fertility [23-25]. The mechanisms whereby these effects take place are unclear. The sex steroids exert both posi- 
tive and negative feedback control on the hypothalamuspituitary system to regulate the release of gonadotropins. The $17 \beta$-estradiol has been shown to inhibit gonadotropin secretion in fish. This may indicate that $17 \beta$-estradiol cause its effects on the testes through alterations in gonadotropin secretion.

Mills [26] reported that $17 \beta$-estradiol treated fish exhibited decreased gonadosomatic index (GSI), altered hepatosomatic index, elevated plasma estradiol, reduced plasma testosterone, and high levels of plasma vitellogenin. Reduced GSI always corresponded with observable histopathological changes indicative of regressed gonads. The present study, Nile tilapia was exposed to $100 \mu \mathrm{g} \mathrm{L}^{-1}$ of $17 \beta$-estradiol for 30 days showed this intersex (testes-ova). These obtained results agree with the previously study, exposure to estrogenic chemicals during the critical periods of sex differentiation has induced testis-ova in several fish species [27, 28].

As suggested by Arcand-Hoy and Benson [29], 17 $\beta$ estradiol given to the male fish can disturb the hypothalamus-pituitary-gonadal axis in which several hormones, including androgens, normally regulates sexual development, sexual physiology, and sexual behavior. Since androgens, also in male regulate secondary sexual characters and reproductive behavior, a disruption of the androgen synthesis or the processes in which androgens participate can cause severe effects [21].

Gimeno and colleague [10] indicated the role of estrogens in the induction of intersex gonads in adult gonochoristic species seems similar to that of the normal process of sex reversal in hermaphrodite species. Indeed, the treatment of juvenile male black porgy, Acanthopagrus schlegeli, a protandrous hermaphrodite marine fish, with $17 \beta$-estradiol caused the regression of the testes and the lack of spermiation, as well as the induction of precocious sex change, as shown by the appearance of oocytes [30].

In conclusion, the present study shows that waterborne exposure to the xenoestrogens 17 $\beta$-estradiol cause's severe effects on the reproductive system of male Nile tilapia.

\section{ACKNOWLEDGEMENTS}

This study was funded by the Thailand Research Fund and the Commission on Higher Education: Research Grant for Mid-Career University Faculty 2008 (RMU5180001) and in part by Mahidol University International College, and Faculty of Science, Mahidol University.

\section{REFERENCES}

[1] Vos, J.G., Dybing, E., Greim, H.A., Ladefoged, O., Lambre, C., Tarazona, J.V., Brandt, I. and Vethaak, A.D. (2000) Health effects of endocrine-disrupting chemicals on wildlife, with special reference to the European situation. Critical Reviews in Toxicology, 30, 71-133.

[2] Endocrine Disruptor Screening and Testing Advisory Committee (EDSTAC). (1998) Endocrine disruptor screening and testing advisory committee final report.

[3] Organization for Economic Co-operation and Development (OECD). (1996) Endocrine disruptor testing and assessment.

[4] World Health Organization. (2002) Global Assessment of the state-of-the-science of Endocrine Disruptors. WHO/ PCS/EDC/02.2. International Program on Chemical Safety.

[5] Adami, H.O., Bergstrom, R., Mohner, M., Zatonski, W., Storm, H., Ekbom, A., Tretli, S., Teppo, L., Ziegler, H. and Rahu, M. (1994) Testicular cancer in nine northern European countries. International Journal of Cancer, 59, 33-38.

[6] Toppari, J., Larsen, J.C., Christiansen, P., Giwercman, A., Grandjean, P., Guillette, L.J., Jegou, B., Jensen, T.K., Jouannet, P., Keiding, N., Leffers, H., McLachlan, J.A., Meyer, O., Muller, J., Rajpert-De Meyts, E., Scheike, T., Sharpe, R., Sumpter, J. and Skakkebaek, N.E. (1995) Male reproductive health and environmental chemicals with estrogenic effects. Ministry of Environment and Energy, Copenhagen, Denmark. Miljoprojekt 290, Danish EPA.

[7] Hutson, J., Baker, M., Terada, M., Zhou, B. and Paxton, G. (1994) Hormonal control of testicular descent and the cause of cryptorchidism. Reproduction, Fertility and Development, 6, 151-156.

[8] Davis, D.L., Gottlieb, M.B. and Stampnitzky, J.R. (1998) Reduced ratio of male to female births in several industrial countries: A sentinel health indicator? The Journal of the American Medical Association, 279, 1018-1023.

[9] Baronti, C.R., D’Ascenzo, C.G., Di Corcia, A., Gentili, A. and Samperi, R. (2000) Monitoring natural and synthetic estrogens at activated sludge sewage treatment plants and in receiving river water. Environmental Science and Technology, 34, 5059-5066.

[10] Gimeno, S., Komen, H., Gerritsen, A.G.M. and Bowmer, T. (1998) Feminisation \{PRIVATE "TYPE = PICT; ALT = next term" of young males of the common \{PRIVATE "TYPE = PICT; ALT = previous term" $\}$ carp, $\{$ PRIVATE "TYPE = PICT; ALT = next term" $\}$ Cyprinus carpio, exposed to 4-tert-pentylphenol during sexual differentiation. Aquatic Toxicology, 43, 77-92.

[11] van der Kraack, G., Hewitt, M., Lister, A., McMaster, M.E. and Munkittrick, K.R. (2001) Endocrine toxicants and reproductive success in fish. Human and Ecological Risk Assessment, 7, 1017-1025.

[12] Tyler, C.R., Jobling, S. and Sumpter, J.P. (1998) Endocrine disruption in wildlife: A critical review of the evidence. Critical Reviews in Toxicology, 28, 319-361.

[13] Rasmussen, T.H., Teh, S.J., Bjerregaard, P. and Korsgaard, B. (2005) Anti-estrogen prevents xenoestrogeninduced testicular pathology of eelpout (Zoarces viviparus). Aquatic Toxicology, 72, 177-194.

[14] American Public Health Association (APHA). (2005) Standard methods for the examination of water and wastewater. 21st Edition, Washington, D.C.

[15] Humason, G.L. (1972) Animal tissue techniques. 3rd Edition, W.H. Freeman and Company, San Francisco. 
[16] Gupta, S. (1975) The development of carp gonads in warm water aquaria. Journal of Fish Biology, 7, 775-782.

[17] Nagahama, Y. (1983) The functional morphology of teleost gonads. In: W.S. Hoar, D.F. Randall, and E.M. Donaldson, Eds., Academic Press, Orlando, 223-264.

[18] Goodbred, S.L., Gilliom, R.J., Gross, T.S., Denslow, N.P., Bryant, W.L. and Schoeb, T.R. (1997) Reconnaissance of $17 \beta$-estradiol, 11-ketotestosterone, vitellogenin, and gonad histopathology in common carp of United States streams. Geological Survey Open-File Report 96-627, Sacramento (CA), U.S.

[19] Muller, A.M.F., Makropoulos, V. and Bolt, H.M. (1995) Toxicological aspects of oestrogen-mimic xenobiotics present in the environment. Toxicology and Ecotoxicology News, 2, 68-73.

[20] van den Belt, K., Wester, P.W., van der Ven, L.T.M., Verheyen, R. and Witters, H. (2002) Effects of ethynylestradiol on the reproductive physiology in zebrafish (Danio rerio): Time dependency and reversibility. Environmental Toxicology and Chemistry, 21, 767-775.

[21] Wibe, A.E., Rosenqvist, G. and Jenssen, B.M. (2002) Disruption of male reproductive behavior in threespine stickleback Gasterosteus aculeatus exposed to $17 \beta$-estradiol. Environmental Research, 90, 136-141.

[22] Peters, R.E.M., Courtenay, S.C., Cagampan, S., Hewitt, M.L. and MacLatchy, D.L. (2007) Effects on reproductive potential and endocrine status in the mummichog (Fundulus heteroclitus) after exposure to $17 \alpha$-ethynylestradiol in a short-term reproductive bioassay. Aquatic Toxicology, 85, 154-166.

[23] Hiramatsu, N., Hara, A., Hiramatsu, K., Fukada, H., Weber, G., Denslow, N. and Sullivan, C. (2002) Vitellogenin-derived yolk proteins of white perch, Morone americana: Purification, characterization, and vitellogenin receptor binding. Biology of Reproduction, 67,
655-667.

[24] Angus, R.A., Stankoa, J., Jenkins, R.L. and Watson, R.D. (2005) Effects of $17 \alpha$-ethynylestradiol on sexual development of male western mosquitofish (Gambusia affinis). Comparative Biochemistry and Physiology Part C: Toxicology and Pharmacology, 140, 330-339.

[25] Teles, M., Pacheco, M. and Santos, M.A. (2006) Biotransformation, stress and genotoxic effects of $17 \beta$-estradiol in juvenile sea bass (Dicentrarchus labrax L.). Environment International, 32, 470-477.

[26] Mills, L.J., Gutjahr-Gobell, R.E., Haebler, R.A., Borsay Horowitz, D.J., Jayaraman, S., Pruell, R.J., McKinney, R.A., Gardner, G.R. and Zaroogian, G.E. (2001) Effects of estrogenic (o,p'-DDT; octylphenol) and anti-androgenic ( $p, p$ '-DDE) chemicals on indicators of endocrine status in juvenile male summer flounder (Paralichthys dentatus). Aquatic Toxicology, 52, 157-176.

[27] Seki, M., Yokota, H., Maeda, M., Tadokoro, H. and Kobayashi, K. (2003) Effects of 4-nonylphenol and 4-tertoctylphenol on sex differentiation and vitellogenin induction in medaka (Oryzias latipe). Environmental Toxicology and Chemistry, 2, 1507-1516.

[28] Flynn, S.R. and Benfey, T.J. (2007) Effects of dietary estradiol-17 $\beta$ in juvenile shortnose sturgeon, Acipenser brevirostrum, Lesueur. Aquaculture, 270, 405-412.

[29] Arcand-Hoy, L.D. and Benson, W. (1998) Fish reproduction: An ecologically relevant indicator of endocrine disruption. Environmental Toxicology and Chemistry, 17, 49-57.

[30] Chang, C.F., Lau, E.L. and Lin, B.Y. (1995) Stimulation of spermatogenesis or of sex reversal according to the dose of exogenous estradiol-17 $\beta$ in juvenile males of protandrous black porgy, Acanthopagrus schlegeli. General and Comparative Endocrinology, 100, 355-367. 